\title{
Absolute Poverty Measures for the Developing World, 1981-2004
}

\author{
Shaohua Chen and Martin Ravallion ${ }^{*}$ \\ Development Research Group, World Bank
}

We report new estimates of measures of absolute poverty for the developing world over 19812004. A clear trend decline in the percentage of people who are absolutely poor is evident, although with uneven progress across regions. We find more mixed success in reducing the total number of poor. Indeed, the developing world outside China has seen little or no sustained progress in reducing the number of poor, with rising poverty counts in some regions, notably Sub-Saharan Africa. There are encouraging signs of progress in reducing the incidence of poverty in all regions after 2000, although it is too early to say if this is a new trend.

\section{World Bank Policy Research Working Paper 4211, April 2007}

The Policy Research Working Paper Series disseminates the findings of work in progress to encourage the exchange of ideas about development issues. An objective of the series is to get the findings out quickly, even if the presentations are less than fully polished. The papers carry the names of the authors and should be cited accordingly. The findings, interpretations, and conclusions expressed in this paper are entirely those of the authors. They do not necessarily represent the view of the World Bank, its Executive Directors, or the countries they represent. Policy Research Working Papers are available online at http://econ.worldbank.org.

\footnotetext{
Our thanks go to our colleague Prem Sangraula for expert assistance in creating the data sets used here and to many colleagues in the Bank who have helped us in accessing the primary data sources.
} 


\section{Introduction}

Progress against absolute poverty is now a widely accepted yardstick for assessing the overall performance of developing economies. The best data for assessing progress against poverty come from surveys of the living standards of nationally-representative samples of households. In the last 25 years there has been enormous progress in designing, implementing and processing such surveys for developing countries — thanks in large part to the efforts of national statistics agencies throughout the world, and the support of the donor community and international development agencies.

Drawing on these data, this paper provides internally-consistent estimates of a time series of measures of absolute poverty for the developing world, and by region, at roughly three-yearly intervals from 1981 to 2004. We use data from over 500 household surveys spanning 100 countries. We follow exactly the methods outlined in Chen and Ravallion (2004), which was the last up-date of the World Bank’s “global” poverty measures, providing estimates up to 2002. In addition to including new data available since 2004, we have recalculated all prior estimates back to 1981, to incorporate any updates or revisions from past data sources.

The paper also discusses the implications of incorporating an urban-rural poverty line differential. This is of interest given the widely heard popular concerns about the urbanization of the developing world's population and (one expects) of poverty.

The paper begins by reviewing the assumptions and methods and then presents and discusses the results.

\section{Methods for measuring poverty in the developing world ${ }^{1}$}

We rely heavily on nationally-representative household surveys for measuring poverty. This is one of the purposes for which these surveys exist. There is no alternative to using survey data for measuring the distribution of relative consumptions or incomes - "inequality" for short. But there is an alternative source of data on average consumption, namely the national accounts

\footnotetext{
$1 \quad$ Here we only summarize the assumptions and methods; for details see Chen and Ravallion (2001, 2004) and Ravallion et al. (2007).
} 
(NAS). ${ }^{2}$ (Given certain assumptions, one can derive standard poverty measures from the mean and a suitable inequality measure.) We use NAS data in some aspects of our estimation methods, notably in dealing with the fact that different countries do their surveys at different dates, and we want to line them up in time to a common reference date. However, we do not let the NAS data override the survey mean when both are known. In other words, we use the survey at the survey date. In this respect we follow the standard, though not universal, practice in the literature on poverty measurement.

Advocates of replacing the survey mean by the NAS estimate of national income or consumption per capita argue that household surveys underestimate mean income or consumption, due to deliberate under-reporting and selective compliance with random samples. However, it is not clear that the NAS data can provide a more accurate measure of mean household welfare than the survey data that were collected for that purpose. And, even acknowledging the problems of income underreporting and selective survey compliance, there can be no presumption that the discrepancies between survey means and the NAS aggregates (such as private consumption per person) are distribution neutral; more plausibly the main reasons why surveys underestimate consumption or income would also lead them to underestimate inequality. ${ }^{3}$ Furthermore, the NAS-means method is clearly unacceptable when doing an urban-rural split of global poverty measures, allowing for cost-of-living (COL) differences, since neither the inequality measures nor the NAS means would then be valid.

Also following past practice, "poverty" is assessed here using household per capita expenditure on consumption. ${ }^{4}$ The measures of consumption (or income, when consumption is

2 Examples include Bhalla (2002) and Sala-i-Martin (2006).

3 For example, Banerjee and Piketty (2005) attribute up to 40 percent of the difference between the (higher) growth of GDP per capita and (lower) growth of mean household per capita consumption from household surveys in India to unreported increase in the incomes of the rich. Selective compliance with random samples could well be an equally important source of bias, although the sign is theoretically ambiguous; Korinek et al. (2006) provide evidence on the impact of selective non-response for the US. $4 \quad$ The use of a "per capita" normalization is standard in the literature on developing countries. This stems from the general presumption that there is rather little scope for economies of size in consumption for poor people. However, that assumption can be questioned; see Lanjouw and Ravallion (1995). 
unavailable) in the survey data we use are reasonably comprehensive, including both cash spending and imputed values for consumption from own production. But we acknowledge that even the best consumption data need not adequately reflect certain "non-market" dimensions of welfare, such as access to certain public services, or intra-household inequalities. For these reasons, our poverty measures need to be supplemented by other data, such as on infant and child mortality, to obtain a more complete picture of how living standards are evolving. ${ }^{5}$

Our poverty measures are estimated from the primary (unit record or tabulated) survey data. For the poverty measures without an urban-rural split we have used 560 household surveys for 100 low- and middle-income countries, representing 93\% of the population of the developing world. ${ }^{6}$ Only for a subset of these was it feasible to do the urban-rural decomposition. This was done for 87 countries using 208 household surveys. (Details on the specific survey used can be found at: http://iresearch.worldbank.org/PovcalNet/jsp/index.jsp.)

We have not used any secondary sources for measuring poverty at each survey round (unlike all other compilations of distributional data and global poverty measures that we know of), although we do use other data sources for interpolation purposes, given that the surveys of different countries do not coincide in time. Households are ranked by either consumption or income per person. The distributions are weighted by household size and sample expansion factors so that a given fractile (such as the poorest decile) should have the same share of the country-specific population across the sample. Thus our poverty counts give the number of people living in households with per capita consumption or income below the poverty line.

As in past work, we have tried to eliminate obvious comparability problems, either by reestimating the consumption/income aggregates or even dropping a survey when there is little option. However, there are problems that we cannot deal with. It is known that differences in survey methods (such as in questionnaire design) can create non-negligible differences in the

$5 \quad$ The annual World Development Indicators provides data on a broad set of indicators, including poverty measures, but also measures of health and education attainments (World Bank, 2006).

$6 \quad$ Coverage varies across regions, from 78\% in Sub-Saharan Africa to 98\% in Eastern Europe and Central Asia and South Asia. 
estimates obtained for consumption or income. For example, while one-week recall for food consumption is common in surveys, there are some countries that use a longer period, which is likely to give a lower estimate of consumption and hence higher measured poverty.

We use standard additively separable poverty measures for which the aggregate measure is the (population-weighted) sum of individual measures. In this paper we report two such poverty measures. The first measure is the headcount index given by the percentage of population living in households with consumption or income per person below the poverty line. We also give estimates of the number of poor, as obtained by applying the estimated headcount index to the population of each region (under the assumption that the countries without surveys are a random sub-sample of the region). Results are also available from the authors for the poverty gap index, ${ }^{7}$ although the basic patterns reported here are similar.

We take it as axiomatic that simply moving individuals between urban and rural areas (or countries), with no absolute loss in their real consumption, cannot increase the aggregate measure of poverty. Relocation on its own cannot change aggregate poverty. This assumption, in combination with the additivity assumption, implies that we are justified in confining our attention to absolute poverty measures, by which we mean that the poverty line is intended to have a constant real value both between countries and between urban and rural areas within countries.

This does not allow for any welfare effects of relative deprivation in better off countries or urban areas. One cannot rule out welfare costs of relative deprivation, although it is unclear just how important an issue this is likely to be in poor countries. The fact that the poverty lines found across countries tend to have little or no income gradient among poor countries (though a much steeper gradient among developed countries) suggests that relative deprivation is not such an issue for measuring poverty in this setting (Ravallion, 1998). Ravallion and Lokshin (2005) present evidence for one of the poorest countries, Malawi, suggesting that the poorest people

\footnotetext{
$7 \quad$ The poverty gap index is the mean distance below the poverty line as a proportion of the line where the mean is taken over the whole population, counting the non-poor as having zero poverty gaps.
} 
care very little about relative deprivation, with absolute consumption being the dominant concern, although the same study finds that relative deprivation does appear to be a concern for relatively well-off urban residents.

Since its 1990 World Development Report, the World Bank’s “global” poverty measures have mainly been based on an international poverty line of about $\$ 1$ a day; more precisely, the line is \$32.74 per month, at 1993 international purchasing power parity. This is a deliberately conservative definition, being anchored to the poverty lines typical of low-income countries (World bank, 1990; Ravallion et al., 1991). To gauge sensitivity, we also use a line set at twice this value, $\$ 65.48$ per person per month. Following common practice we refer to these as the “\$1 a day" and " $\$ 2$ a day” lines ( $\$ 1.08$ and $\$ 2.15$ would be more precise). The higher line is more representative of what "poverty" means in middle-income developing countries.

The international rural line is converted to local currencies using the Bank's 1993 Purchasing Power Parity (PPP) exchange rates for consumption. PPP exchange rates adjust for the fact that non-traded goods tend to be cheaper in poorer countries. There is more than one way to measure PPP exchange rates. The Geary-Khamis (GK) method used by the Penn World Tables (PWT) uses quantity weights to compute the international price indices; for our purposes, this method give a too high a weight to consumption patterns in richer countries when measuring poverty globally. The EKS method - a multilateral extension of the usual bilateral Fisher index — attempts to correct for this bias. Since 2000 the World Bank's global poverty and inequality measures have been based on the Bank's PPPs, which use the EKS method.

In decomposing our estimates by urban and rural areas, a key issue is how to deal with the fact that the cost-of-living (COL) is generally higher in urban areas. Casual observations suggest that relatively weak internal market integration and the existence of geographically nontraded goods can yield substantial cost-of-living differences between urban and rural areas. Any assessment of the urbanization of poverty that ignored these COL differences would simply not be credible. Yet existing PPP exchange rates used to convert the international line into local currencies do not distinguish rural from urban areas. 
To address this problem we turn to the World Bank's country-specific Poverty Assessments (PA's), which have now been done for most developing countries. These are core reports within the Bank's program of analytic work at country level; each report describes the extent of poverty and its causes in that country. The PA's are clearly the best available source of information on urban-rural differentials for setting international poverty lines. In almost all cases, the PA poverty lines were constructed using some version of the Cost-of-Basic-Needs method. ${ }^{8}$ This aims to approximate a COL index that reflects the differences in prices faced between urban and rural areas, weighted by the consumption patterns of people living in a neighborhood of the country-specific poverty line. This is consistent with the use of an absolute poverty standard across countries.

However, while our method appears to be the best option that is currently feasible, internal consistency is questionable if the urban-rural COL differential varies by income, for then the differential from the PA may not be right for the international poverty lines. If the COL differential tends to rise with income then we will tend to overestimate urban poverty by the $\$ 1$ a day line in middle-income countries relative to low-income countries, given that the PA poverty line will tend to be above the international line for most middle-income countries.

A data constraint that can also create internal inconsistencies is that in setting poverty lines, location-specific prices are typically only available for food goods. Also, while nutritional requirements for good health provide a defensible anchor in setting a reference food bundle, it is less obvious in practice what normative criteria should be applied in defining "non-food basic needs.” In addressing these concerns, the non-food component of the poverty line is typically set according to food demand behavior in each sub-group of the population for which a poverty line is to be determined. Different methods are found in practice, but they share the common feature that the non-food component of the poverty line is found by looking at the non-food spending of people in a neighborhood of the food poverty line, which is the cost for that sub-group of a

$8 \quad$ The precise method used varies from country-to-country, depending on the data available. For an overview of the alternative methods found in practice see Ravallion (1998). 
reference food bundle (which may itself vary according to differences in relative prices or other factors). Depending on the properties of the food Engel curves (notably how much they shift with factors that are not deemed relevant to absolute welfare comparisons), this may introduce some degree of relativism, or just plain noise, into the urban-rural poverty comparisons.

We used the ratio of the urban poverty line to the rural line from the PA (generally the one closest to 1993 if there is more than one) to obtain an urban poverty line for each country corresponding to its PPP-adjusted “\$1 a day” rural line. On average, the urban poverty line is about 30\% higher than the rural line, although there are marked differences between countries, with a tendency for the differential to be higher in poorer countries (Ravallion et al., 2007), which is consistent with one's expectation that transport costs and other impediments to internal market integration are higher in poor countries.

The urban population data are from the latest available issue of World Urbanization Prospects (United Nations, 2005). There are undoubtedly differences in the definitions used between countries, which we can do little about here (for further discussion see Cohen, 2004, and Ravallion et al., 2007). The WUP estimates are based on actual enumerations whenever they are available. The WUP web site provides details on data sources and how specific cases were handled; see http://esa.un.org/unup/.

Naturally the surveys are scattered over time. We estimate the poverty measures for nine “reference years”, 1981, 1984, 1987, 1993, 1996, 1999, 2002 and 2004 (adding 2004 to the years reported in Chen and Ravallion, 2004, though revising all past estimates). Our estimates for the urban-rural breakdown are for 1993, 1996, 1999 and 2002. To estimate poverty at a given reference year we "line up" the surveys in time using the same method described in Chen and Ravallion (2004), which also describes our interpolation method when the reference date is between two surveys. 


\section{Results and discussion}

Tables 1 and 2 give our aggregate results for the two poverty lines and for both the headcount index and the absolute number of poor judged against each line.

Aggregating across regions, we find a trend decline in the headcount indices; for both lines, the trend is about $0.8 \%$ points per years over $1981-2004 .^{9}$ This is more than the rate of poverty reduction of $0.6 \%$ points per year that would be more than enough to halve the $1990 \$ 1 \mathrm{a}$ day poverty rate by 2015, which is first of the first of the Millennium Development Goals (MDG1).

However, there are three important qualifications suggested by our results. Firstly, even achieving MDG1 will leave a great many very poor people. The trend over 1981-2004 in the number living below $\$ 1$ a day is about 17 million fewer people living under $\$ 1$ a day per year. ${ }^{10}$ At this rate of decline, there will still be over 800 million people living under $\$ 1$ a day in 2015, even though the 1990 poverty rate will have been halved. ${ }^{11}$

Secondly, progress has been slower for the \$2 line. Projecting our series forward linearly implies a headcount index for this line of about $40 \%$ in 2015 , well short of the $30 \%$ figure needed to halve the 1990 index. $^{12}$ The number of people living below the $\$ 2$ line actually rose over most of the period, only falling briefly in the mid 1990s and since the end of the 1990s. Projecting forward linearly to 2015 we can expect about 2.8 billion people living under $\$ 2$ a day (2 billion living between $\$ 1$ and $\$ 2) .{ }^{13}$ One should, of course, be wary of such linear projections. We do see signs of falling numbers of people living under \$2 a day after about 2000, though it is

\footnotetext{
$9 \quad$ The regression coefficients on time are -0.83 (standard error $=0.09$ ) and -0.77 (s.e. $=0.05$ ) for $\$ 1$ and $\$ 2$ respectively.

10 The regression coefficient on time is -16.80 (s.e. $=2.64$ ).

11 The estimate implied by a linear extrapolation based on a regression of the number of poor on time is 801.5 million with a standard error of 61.6 million. An exponential growth model (regressing log of the number of poor on time) gives 852.6 million poor by 2015, with a standard error of 40.3 million. 12 The estimate for 2015 implied by a linear regression on time is $40.7 \%$ (s.e. $=1.3 \%$ ).

13 The regression for $\$ 2$ a day implies 2778 million poor in 2015 (s.e.=88 million). (2782 million using an exponential specification, with s.s. $=93$ million.)
} 
clearly too early to call this a sustained reversal. However, it is clear that projected success in achieving MDG1 depends critically on the level of the poverty line.

The relatively slower progress in reducing “\$2-a-day poverty” reflects, of course, the rising numbers of people living between $\$ 1$ and $\$ 2$. That is not too surprising; those escaping extreme poverty will not be rapidly entering the global "middle-class.” A more positive perspective on these numbers is obtained if we note that there has been even more rapid expansion in the number of people living above $\$ 2$ a day. Based on Tables 1 and 2, we can derive the population growth rates over this period for the three groups: those living under $\$ 1$ a day, those living between $\$ 1$ and $\$ 2$, and those living over $\$ 2$. The annual exponential growth rates (obtained by regressing the log population on time) for these three groups are $-1.4 \%, 1.9 \%$ and $3.5 \%$ respectively (with standard errors of $0.2 \%, 0.4 \%$ and $0.1 \%$ ).

Thirdly, China naturally carries the largest weight in these calculations. Tables 1 and 2 also give our estimates excluding China. The trend rates of decline in the headcount indices are roughly halved when one focuses on the developing world outside China. ${ }^{14}$ If the trend rate of decline over 1981-2004 in the headcount index for \$1 a day continues until 2015 then the index will have fallen to $16 \%$ - more than half its 1990 value. ${ }^{15}$ When we exclude China, we find a fairly static picture in terms of the number of people living under \$1 a day, with no clear trend, and a clear trend increase in the number of poor by the $\$ 2$ a day poverty line, which shows little sign of the possible reversal after 2000 indicated by the series including China (Table 2).

The aggregate pattern of population growth rates across the three "income” groups — under $\$ 1$, between $\$ 1$ and $\$ 2$ and over $\$ 2$ - changes radically when we focus on the developing world outside China. We now find annual growth rates of $0.1 \%$ (s.e.=0.1\%), 2.4\% (0.2) and $2.5 \%(0.1)$ respectively.

14 The regression coefficients on time are -0.45 (s.e. $=0.03$ ) and -0.28 (s.e. $=0.03$ ) for $\$ 1$ and $\$ 2$ respectively.

15 The 2015 extrapolation based on a regression of the headcount index on time implies an index in 2015 of $16.00 \%$ with a standard error of $0.55 \%$. So the MDG goal of about $13.6 \%$ (outside China) implied by Table 1 is also outside the $95 \%$ confidence interval for this forecast. 
It should also be noted that some features of the overall series also reflect events in China. The sharp reduction in the poverty count in the early 1980s (particularly for the lower line) is largely due to China; over 200 million fewer people are found to have lived under \$1 a day in 1984 than $1981{ }^{16}$ China is also responsible for the slight drop in the number of poor globally in the mid 1990s. ${ }^{17}$

So far we have focused on the aggregates across regions. It is clear from Tables 1 and 2 that the evolution of the poverty measures over the period as a whole is strikingly different across regions, as is evident from Figure 2. We find sharply falling numbers of poor in East Asia (by both lines). Both the numbers and proportions of poor were generally rising in Eastern Europe and Central Asia, though showing a marked improvement after 2000. We find generally rising numbers of poor but falling percentages in Latin America and the Middle-East and North Africa, although with some signs of improvement after 2000, and a trend decline in the number of people under the \$1 line in MENA. We find falling percentages of poor in South Asia but a fairly static count of the number of poor under $\$ 1$ a day, and a rising count for the higher one.

We find a clear indication of rising poverty counts in Sub-Saharan Africa (SSA) for both lines, though with encouraging signs of a reduction in the percentage below the line after 2000, in keeping with other regions. The rate of decline in SSA's \$1 a day poverty is about one \% point per year from 1999 to 2004; in absolute terms this is slightly higher than the rate of decline for the developing world as a whole, although (given Africa's higher than average poverty rate) the proportionate rate of decline over 1999-2004 is still lower than average. Using the \$2 line,

\footnotetext{
16 The agrarian reforms that commenced in the late 1970s are believed to have brought a huge reduction in the number of poor over a fairly short period. For further discussion of both the data for China and the various policy reforms impinging on poverty over the 1980s and 1990s see Ravallion and Chen (2007).

17 The main reason for the sharp reduction in poverty in China in the mid-1990s was probably that the government brought the procurement prices for its foodgrain quotas up to market levels, which entailed a substantial drop in its (implicit) taxation of farmers; for further discussion see Ravallion and Chen (2007).
} 
we still see progress in SSA since the 1990s, although the rates of decline in the incidence of poverty lag behind the developing world as a whole.

The regional composition of poverty has changed dramatically. Since the decline in poverty between 1981 and 1984 is rather special (being largely due to China), let us focus on 1984 and 2004. In 1984, the region with the highest share of the world's \$1 a day poor (assuming there are none in developed countries) was East Asia, with 44\% of the total; one third of the poor were in China at that time. By 2004, East Asia's share had fallen to 17\% (13\% for China). This was made up largely by the rise in the share of the poor in South Asia (from 35\% in 1984 to $46 \%$ in 2004) and (most strikingly) Sub-Saharan Africa, which saw its share of the number of people living under \$1 a day rise from 16\% in 1984 to 31\% 20 years later. Projecting these numbers forward to 2015 , SSA's share of the " $\$ 1$ a day poor" will be almost $40 \%{ }^{18}$

When we focus on the sub-period for which the urban-rural decomposition is currently feasible, namely 1993-2002, the aggregate results point to a somewhat higher overall poverty rate than found in Tables 1 and 2. Figure 1 gives the aggregate poverty measures with and without the correction for a higher urban cost of living. For example, when we allow for an urban-rural differential in the cost-of-living, we find that a \$1 a day headcount index in 1993 that is about 2.3\% points higher (27.9\% versus 25.6\%, from Table 1). More than 100 million people are added to the global count of the poor when we allow for the higher cost of living in urban areas, and about half of the 100 million come from South Asia and one third from SSA. Tables 3 and 4 give detailed results on the urban-rural breakdown for 1993 and 2002 using the $\$ 1$ a day line; for more complete results see Ravallion et al. (2007).

The change in methodology makes much less differences to the trends over time. Over the period 1993-2002, both methods indicate a 5.2\% point decline in the "\$1 a day" poverty rate. The proportionate rate of decline is of course slightly lower when one allows for the urban-rural poverty-line differential. This was sufficient to reduce the overall count of the number of poor

18 Regressing SSA's share of the poor on time the prediction for 2015 is $39.4 \%$ (s.e. $=1.2 \%$ ). 
by about 100 million people (105 million when using the same line for urban and rural areas and 98 million when one allows for a higher urban poverty line).

We find that rural poverty incidence is appreciably higher than urban. The $\$ 1$ a day rural poverty rate in 2002 of $30 \%$ is more than double the urban rate. Similarly, while $70 \%$ of the rural population live below $\$ 2$ a day, the proportion in urban areas is less than half that figure. The rural share of poverty in 2002 is 75\% using the \$1 a day line, and slightly lower using \$2.

We find a marked difference between urban and rural areas in how poverty is changing over time. The rural poverty rate fell much more than the urban rate. Our results indicate a count of 98 million fewer poor by the "\$1 a day” standard over 1993-2002, which is the net effect of a decline by 148 million in the number of rural poor and an increase of 50 million in the number of urban poor (Table 3). Similarly, the progress in reducing the total number of people living under \$2 a day in rural areas by 116 million came with an increase in the number of urban poor of 65 million, giving a net drop in the poverty count of only 51 million (Ravallion et al., 2007).

The lack of a trend in the overall urban poverty rate implies that the main proximate causes of the overall decline in the poverty rate are (i) urban population growth (at a given urban-rural poverty rate differential) and (ii) falling poverty incidence within rural areas. On the relative importance of these two factors see Ravallion et al. (2007), which decomposes the total change in poverty into components due to urban poverty reduction, rural poverty reduction and the population shift from rural to urban areas (each with appropriate weights to assure that the decomposition “adds up”). Using this decomposition, one finds that $4.0 \%$ points of the $5.2 \%$ point decline in the aggregate \$1 a day poverty rate between 1993 and 2002 is attributed to lower rural poverty, $0.3 \%$ points to lower urban poverty, and $1.0 \%$ point to urbanization (Ravallion et al., 2007). Three-quarters of the aggregate poverty reduction is accountable to falling poverty within rural areas. One-fifth is attributed to urbanization. Urban poverty reduction has clearly played a more important role in aggregate poverty reduction using the \$2 line than the \$1 line. Of the total decline in the poverty rate for the higher line of $8.7 \%$ points, $4.8 \%$ is attributed to 
rural poverty reduction (55\% of the total), $2.3 \%$ to urban, and $1.6 \%$ to the population shift effect (Ravallion et al., 2007).

For the "\$1 a day" line, we find that the urban share of the poor is rising over time, from $19 \%$ in 1993 to $25 \%$ in 2002 . The ratio of urban poverty incidence to total poverty incidence has also risen with urbanization, implying that the poor have been urbanizing faster (in proportionate terms) than the population as a whole.

Using the "\$2 a day" line, we find a slightly higher share of the poor living in urban areas, but that this share has been rising at a slower pace than for the $\$ 1$ a day line. There is also a sign of a deceleration in the urbanization of poverty using the \$2 line (Ravallion et al., 2007).

There are notable differences across regions in the urbanization of poverty. In 2002, the rural headcount index for East Asia was nine times higher than the urban index, but only 16\% higher in South Asia, the region with the lowest relative difference in poverty rates between the two sectors. The contrast between China and India is particularly striking. We find that poverty incidence in urban China in 2002 was barely 4\% of the rural rate, while it was $90 \%$ for India. Urban poverty incidence in China is unusually low relative to rural, though problems in the available data for China (notably in the fact that recent migrants to urban areas are undercounted in the urban surveys) are probably leading us to underestimate the urban share of the poor in that country. ${ }^{19}$

We find that the urban share of the poor is lowest in East Asia (6.6\% of the $\$ 1$ a day poor lived in urban areas in 2002), due in large part to China. The urban share of the poor is highest in Latin America, where 59\% of the $\$ 1$ a day poor, and 66\% of the $\$ 2$ a day poor lived in urban areas in 2002. This is the only region in which more of the "\$1 a day" poor live in urban than rural areas (the switch occurred in the mid-1990s).

South Asia and SSA turn out to be the regions with highest urbanization of poverty at given overall urbanization, due to their relatively high urban poverty rates relative to rural; these are also the regions with the highest overall poverty rates (Ravallion et al., 2007). In 2002,

$19 \quad$ For further discussion see Ravallion and Chen (2007). 
almost half (46\%) of the world's urban poor by the $\$ 1$ a day line are found in South Asia, and another third (34\%) are found in SSA; these proportions fall appreciably when one focuses on the $\$ 2$ a day line, for which $39 \%$ and $22 \%$ of the urban poor are found in South Asia and SSA respectively.

In the aggregate and in most regions, we find that poverty incidence fell in both urban and rural sectors over the period as a whole (though with greater progress against rural poverty in the aggregate). LAC and SSA are exceptions. There rising urban poverty came with falling rural poverty. The (poverty-reducing) population shift and rural components for LAC and SSA were offset by the (poverty-increasing) urban component.

While the urban poverty rate for the developing world as a whole was relatively stagnant over time for $\$ 1$ a day, this is not what we find in all regions. Indeed, the urban poverty rate is falling relative to the national rate in both East Asia and ECA, attenuating the urbanization of poverty; indeed, in ECA the urban share of the poor is actually falling over time - a "ruralization" of poverty — even while the urban share of the total population has risen, though only slightly. (There is the hint of a ruralization of \$2 a day poverty in East Asia from the late 1990s, again due to China.) The ruralization of poverty in ECA is not surprising, as it is consistent with other evidence suggesting that the economic transition process in this region has favored urban areas over rural areas (World Bank, 2005). This has also been the case in China since the mid-1990s (Ravallion and Chen, 2007).

South Asia shows no trend in either direction in the urban poverty rate relative to the national rate, and the region has also had a relatively low overall urbanization rate, with little sign of a trend increase in the urban share of the poor. The population shift component of poverty reduction is also relatively less important in South Asia.

The urban poverty rate relative to the national rate has shown no clear trend in SSA, although rapid urbanization of the population as a whole has meant that a rising share of the poor are living in urban areas. 


\section{Conclusions}

We have provided new estimates of the aggregate poverty measures and their regional and urban-rural breakdown for the developing world based on household survey data. The longest time series we have estimated here follows past practice in the World Bank's global poverty measures of not incorporating an allowance for the higher cost of living in urban areas. We have provided an update of these measures to 2004. We find a clear trend decline in the percentages of people below each of the international poverty lines, though naturally with less progress in reducing the numbers of poor. Indeed, using our higher line, the count of the poor has been rising over most of the period, and there has not been much progress in reducing the number of people living below our lower line (at roughly $\$ 1$ a day) when one looks at the developing world outside China. However, it is encouraging that we do find evidence of progress in reducing poverty after about the year 2000 .

The overall picture is fairly similar when we allow for the higher cost of living in urban areas, although this change in methodology adds about 100 million to the count of the number of people living under $\$ 1$ a day at rural prices. We find that three-quarters of the developing world's poor live in rural areas, when assessed by international poverty lines that aim to have a constant real value (between countries and between urban and rural areas within countries). The poor are urbanizing faster than the population as a whole, reflecting a lower-than-average pace of urban poverty reduction. Over 1993-2002, while 50 million people were added to the count of $\$ 1$ a day poor in urban areas, the aggregate count of the poor fell by about 100 million, thanks to a decline of 150 million in the number of rural poor. 


\section{References}

Banerjee A, Piketty T (2005) “Top Indian Incomes, 1922-2000”, The World Bank Economic Review, 19: 1-20.

Bhalla S (2002) Imagine There's No Country: Poverty, Inequality and Growth in the Era of Globalization (Washington DC: Institute for International Economics).

Chen S, Ravallion M (2001) “How Did the World's Poor fare in the 1990s?”, Review of Income and Wealth, 47(3): 283-300.

Chen S, Ravallion M (2004) “How Have the World's Poorest Fared Since the Early 1980s?”, World Bank Research Observer, 19(2): 141-170.

Cohen, B (2004) “Urban Growth in Developing Countries: A Review of Current Trends and a Caution Regarding Existing Forecasts,” World Development 32(1): 35-51.

Korinek A, Mistiaen J, Ravallion M (2006) “Survey Nonresponse and the Distribution of Income.” Journal of Economic Inequality, 4(2): 33-55.

Lanjouw P, Ravallion M (1995) “Poverty and Household Size,” Economic Journal, 105: 1415-1435.

Ravallion M (1998) Poverty Lines in Theory and Practice. Living Standards Measurement Study Working Paper No. 133. Washington, DC: World Bank.

Ravallion M, Chen S (2007) “China’s (Uneven) progress Against Poverty,” Journal of Development Economics, 82(1): 1-42.

Ravallion M, Chen S, Sangraula P (2007) "New Evidence on the Urbanization of Global Poverty,” Policy Research Working Paper 4199, World Bank.

Ravallion M, Datt G, van de Walle D (1991) “Quantifying Absolute Poverty in the Developing World”, Review of Income and Wealth 37: 345-361.

Ravallion M, Lokshin M (2005) “Who Cares about Relative Deprivation?” Policy Research Working Paper 3782, World Bank, Washington DC.

Sala-i-Martin X (2006) “The World Distribution of Income: Falling Poverty and Convergence. Period,” Quarterly Journal of Economics, 121(2): 351-397. 
United Nations (2005) World Urbanization Prospects: The 2005Revision (Population Division, Department of Economic and Social Affairs, New York).

World Bank (1990) World Development Report: Poverty. (Oxford University Press, New York).

World Bank (2005) Growth, Poverty and Inequality: Eastern Europe and the Former Soviet Union, Washington DC: World Bank.

World Bank (2006) World Development Indicators. Washington DC: World Bank. 
Figure 1: Evolution of poverty measures over time, 1981-2004

(a) Headcount indices

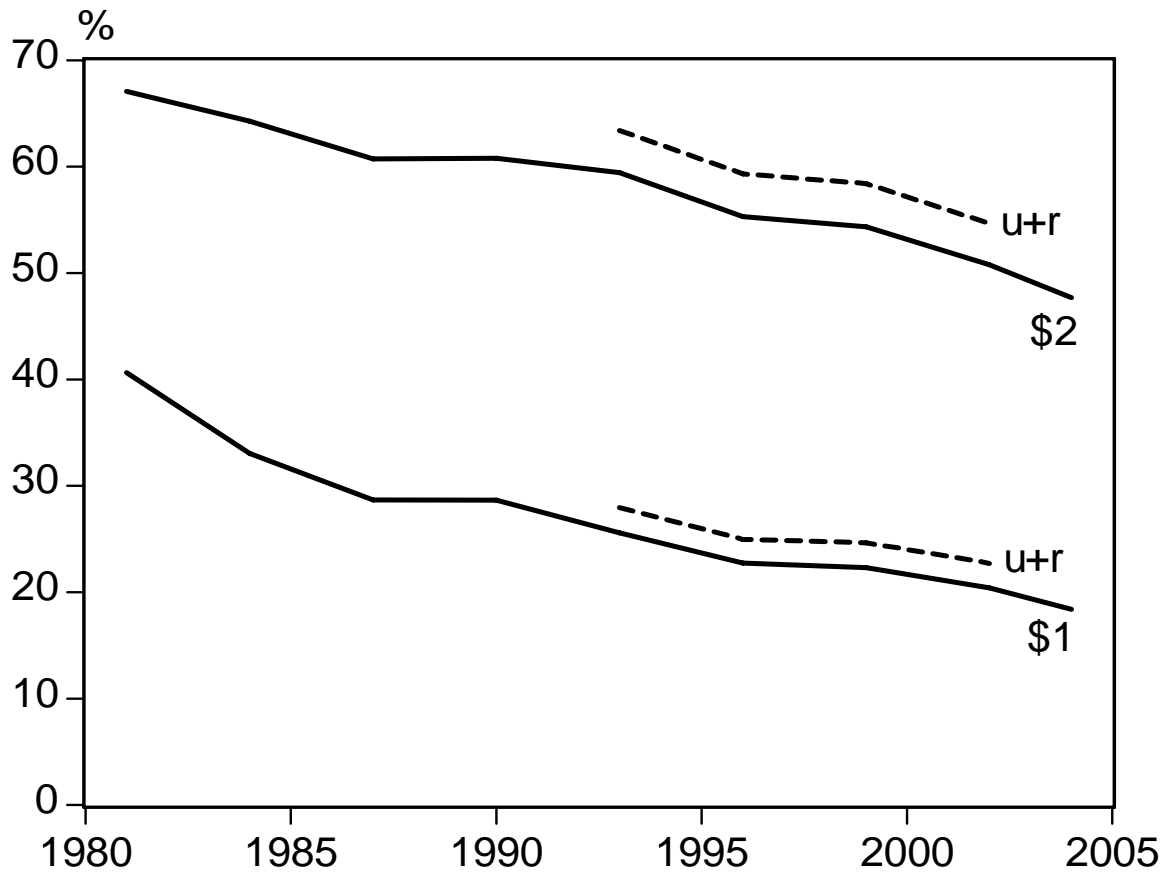

(b) Number of people below poverty lines

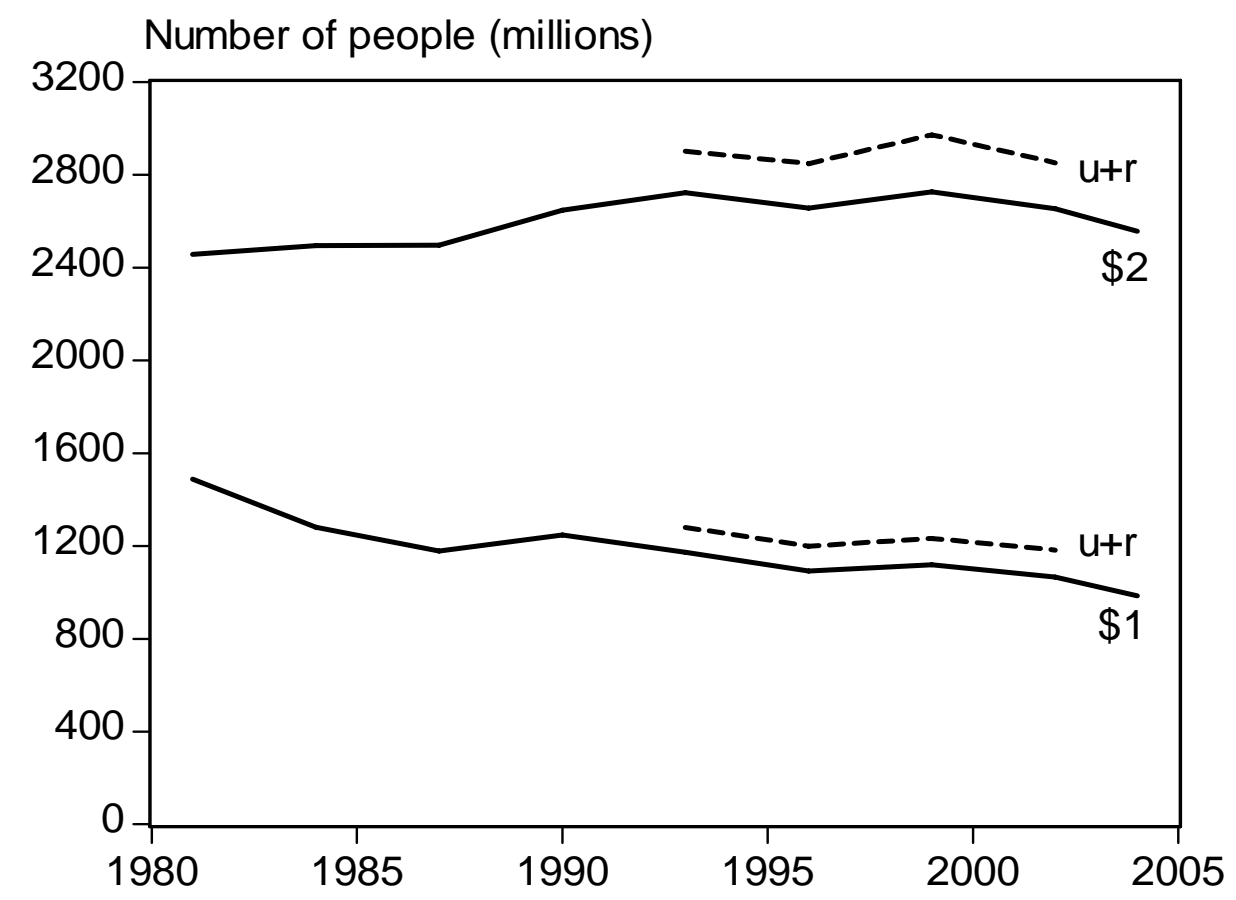

Note: The series labeled “ $\mathrm{u}+\mathrm{r}$ ” incorporates the urban-rural poverty line differential 
Figure 2: Poverty measures by region 1981-2004

(a) Headcount index

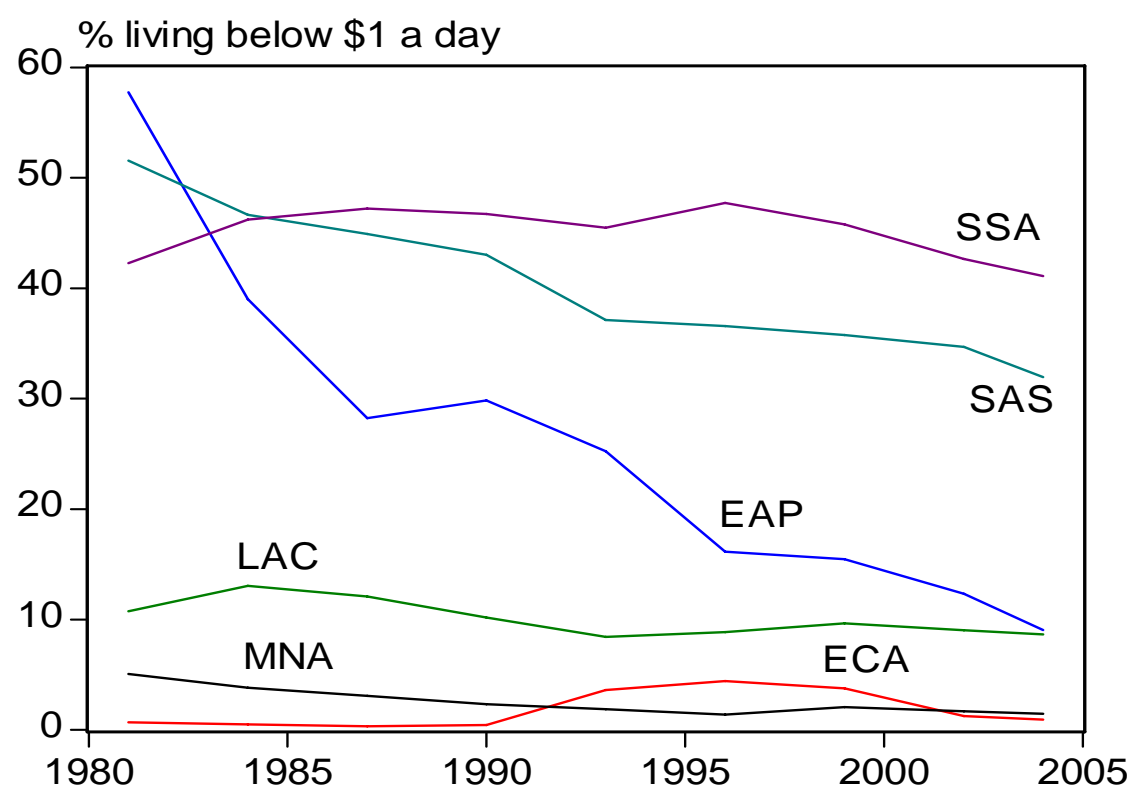

(b) Number of people

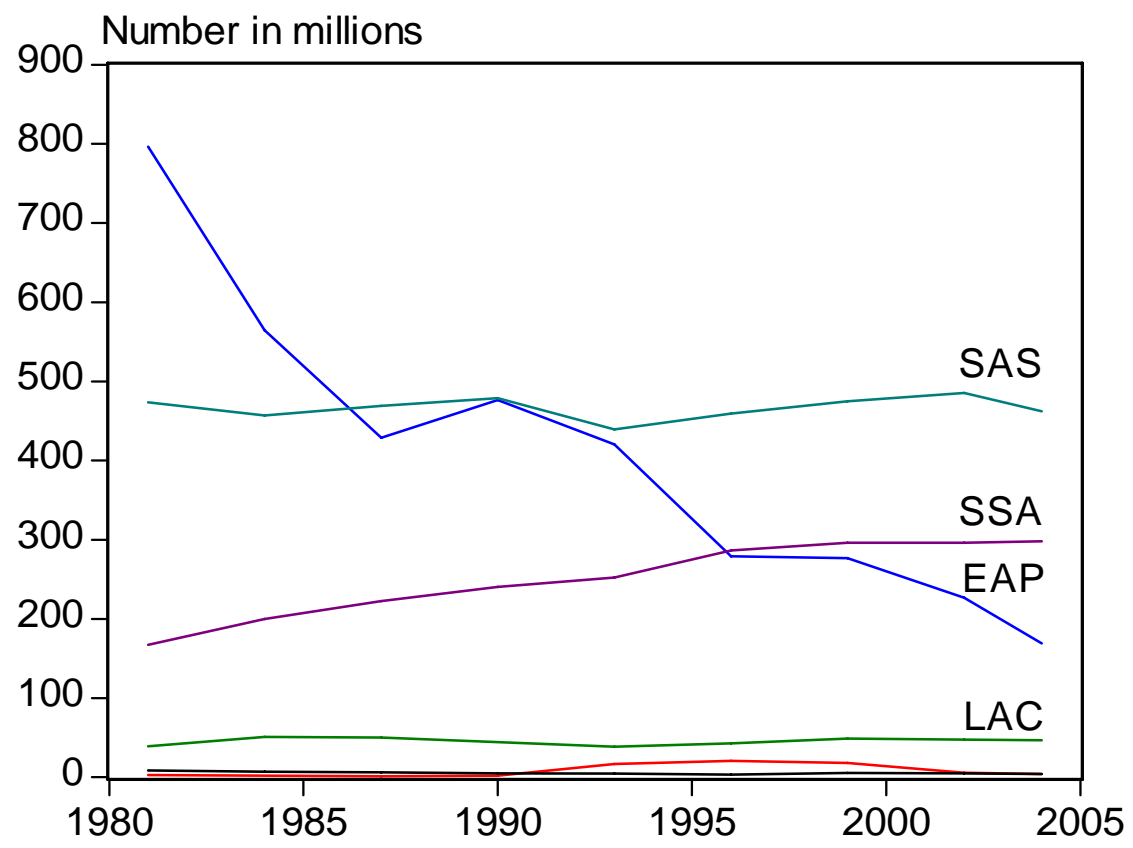

Note: LAC=Latin America and the Caribbean; ECA=Eastern Europe and Central Asia; SSA=Sub-Saharan Africa; SAS=South Asia; MNA=Middle-East and North Africa; EAP=East Asia and Pacific. 
Table 1: Poverty measures for $\$ 1$ a day

(a) Percentage of population

\begin{tabular}{|c|c|c|c|c|c|c|c|c|c|}
\hline \multicolumn{3}{|l|}{ Region } & 1981 & 1984 & 1987 & 1990 & 1993 & 1996 & 1999 \\
\hline \multicolumn{3}{|c|}{ East-Asia and Pacific (EAP) } & 57.73 & 39.02 & 28.23 & 29.84 & 25.23 & 16.14 & 15.46 \\
\hline \multicolumn{3}{|c|}{ Of which China } & 63.76 & 41.02 & 28.64 & 32.98 & 28.36 & 17.37 & 17.77 \\
\hline \multicolumn{3}{|c|}{ Eastern-Europe+Central Asia (ECA) } & 0.70 & 0.51 & 0.35 & 0.46 & 3.60 & 4.42 & 3.78 \\
\hline \multicolumn{3}{|c|}{ Latin America+Caribbean (LAC) } & 10.77 & 13.07 & 12.09 & 10.19 & 8.42 & 8.87 & 9.66 \\
\hline \multicolumn{3}{|c|}{ Middle East+North Africa (MNA) } & 5.08 & 3.82 & 3.09 & 2.33 & 1.87 & 1.69 & 2.08 \\
\hline \multicolumn{3}{|c|}{ South Asia (SAS) } & 49.57 & 45.43 & 45.11 & 43.04 & 36.87 & 36.06 & 34.92 \\
\hline \multicolumn{3}{|l|}{ Of which India } & 51.75 & 47.94 & 46.15 & 44.31 & 41.82 & 39.94 & 37.66 \\
\hline \multicolumn{3}{|c|}{ Sub-Saharan Africa (SSA) } & 42.26 & 46.20 & 47.22 & 46.73 & 45.47 & 47.72 & 45.77 \\
\hline \multicolumn{3}{|c|}{ Total } & 40.14 & 32.72 & 28.72 & 28.66 & 25.56 & 22.66 & 22.10 \\
\hline \multicolumn{3}{|c|}{ Total excl.China } & 31.35 & 29.69 & 28.75 & 27.14 & 24.58 & 24.45 & 23.54 \\
\hline \multicolumn{10}{|c|}{ (b) Number of people } \\
\hline Region & 1981 & 1984 & 1987 & 1990 & 1993 & 1996 & 1999 & 2002 & 2004 \\
\hline EAP & 796.40 & 564.30 & 428.76 & 476.22 & 420.22 & 279.09 & 276.54 & 226.77 & 169.13 \\
\hline China & 633.66 & 425.27 & 310.43 & 374.33 & 334.21 & 211.44 & 222.78 & 176.61 & 128.36 \\
\hline ECA & 3.00 & 2.27 & 1.61 & 2.16 & 16.94 & 20.87 & 17.90 & 6.01 & 4.42 \\
\hline LAC & 39.35 & 50.90 & 50.00 & 44.60 & 38.83 & 42.96 & 49.03 & 48.13 & 47.02 \\
\hline MNA & 8.81 & 7.26 & 6.41 & 5.26 & 4.53 & 4.38 & 5.67 & 4.88 & 4.40 \\
\hline SAS & 455.18 & 445.05 & 471.14 & 479.10 & 436.74 & 452.91 & 463.40 & 469.55 & 446.20 \\
\hline India & 363.72 & 359.41 & 368.60 & 376.44 & 376.14 & 378.91 & 376.25 & 377.84 & 370.67 \\
\hline SSA & 167.53 & 199.78 & 222.80 & 240.34 & 252.26 & 286.21 & 296.07 & 296.11 & 298.30 \\
\hline Total & 1470.28 & 1269.56 & 1180.73 & 1247.68 & 1170.17 & 1087.81 & 1108.61 & 1051.46 & 969.48 \\
\hline Total excl.China & 836.62 & 844.29 & 870.30 & 873.35 & 835.96 & 876.37 & 885.83 & 874.85 & 841.12 \\
\hline
\end{tabular}

Source: Author's calculations for this paper. 
Table 2: Poverty measures for $\$ 2$ a day

(a) Percentage of population

\begin{tabular}{|c|c|c|c|c|c|c|c|c|c|}
\hline Region & 1981 & 1984 & 1987 & 1990 & 1993 & 1996 & 1999 & 2002 & 2004 \\
\hline EAP & 84.80 & 77.17 & 68.53 & 69.73 & 65.04 & 52.49 & 49.34 & 41.68 & 36.58 \\
\hline China & 88.12 & 79.00 & 68.64 & 72.16 & 68.13 & 53.34 & 50.05 & 40.94 & 34.89 \\
\hline ECA & 4.60 & 3.93 & 3.08 & 4.31 & 16.53 & 17.97 & 18.57 & 12.88 & 9.79 \\
\hline LAC & 28.45 & 32.25 & 29.57 & 26.25 & 24.09 & 25.24 & 25.31 & 24.76 & 22.17 \\
\hline MNA & 29.16 & 25.59 & 24.24 & 21.69 & 21.41 & 21.40 & 23.62 & 21.09 & 19.70 \\
\hline SAS & 88.53 & 87.01 & 86.57 & 85.62 & 82.22 & 82.12 & 80.41 & 79.73 & 77.12 \\
\hline India & 88.92 & 87.89 & 86.98 & 86.30 & 85.33 & 84.12 & 82.67 & 81.37 & 80.36 \\
\hline SSA & 74.52 & 76.98 & 77.36 & 77.05 & 76.09 & 76.42 & 75.85 & 73.81 & 71.97 \\
\hline Total & 66.96 & 64.25 & 60.73 & 60.79 & 59.44 & 55.52 & 54.24 & 50.69 & 47.55 \\
\hline Total excl.China & 59.08 & 58.87 & 57.89 & 56.78 & 56.43 & 56.26 & 55.63 & 53.85 & 51.58 \\
\hline \multicolumn{10}{|c|}{ (b) Number of people (millions) } \\
\hline Region & 1981 & 1984 & 1987 & 1990 & 1993 & 1996 & 1999 & 2002 & 2004 \\
\hline EAP & 1169.74 & 1115.97 & 1040.71 & 1112.93 & 1083.21 & 907.83 & 882.70 & 766.26 & 683.83 \\
\hline China & 875.77 & 819.11 & 744.07 & 819.11 & 802.86 & 649.47 & 627.55 & 524.24 & 452.25 \\
\hline ECA & 19.78 & 17.38 & 14.03 & 20.07 & 77.83 & 84.88 & 87.94 & 60.75 & 46.25 \\
\hline LAC & 103.90 & 125.58 & 122.30 & 114.85 & 111.08 & 122.30 & 128.44 & 131.14 & 120.62 \\
\hline MNA & 50.56 & 48.62 & 50.24 & 48.91 & 51.80 & 55.40 & 64.50 & 60.92 & 59.13 \\
\hline SAS & 813.04 & 852.39 & 904.21 & 953.00 & 973.99 & 1031.48 & 1067.15 & 1115.54 & 1115.77 \\
\hline India & 624.92 & 658.92 & 694.71 & 733.13 & 767.39 & 798.07 & 825.93 & 853.32 & 867.62 \\
\hline SSA & 295.46 & 332.87 & 365.02 & 396.32 & 422.11 & 458.37 & 490.58 & 512.62 & 522.34 \\
\hline Total & 2452.47 & 2492.81 & 2496.50 & 2646.09 & 2721.72 & 2665.66 & 2721.31 & 2647.22 & 2547.94 \\
\hline Total excl. China & 1576.70 & 1673.70 & 1752.42 & 1826.98 & 1918.86 & 2016.19 & 2093.75 & 2122.98 & 2095.69 \\
\hline
\end{tabular}

Note: For region identifiers see Table 1. Source: Author's calculations for this paper. 
Table 3: Urban and rural poverty measures using a poverty line of $\$ 1$ a day

\begin{tabular}{|c|c|c|c|c|c|c|c|c|}
\hline & Numbe & f poor in & illlions & Urban & ount ind & Total & $\begin{array}{c}\text { Urban } \\
\text { share of } \\
\text { the poor } \\
(\%)\end{array}$ & $\begin{array}{c}\text { Urban } \\
\text { share of } \\
\text { population } \\
(\%)\end{array}$ \\
\hline \multicolumn{9}{|l|}{1993} \\
\hline EAP & 28.38 & 407.17 & 435.55 & 5.48 & 35.47 & 26.15 & 6.51 & 31.09 \\
\hline China & 10.98 & 331.38 & 342.36 & 3.33 & 39.05 & 29.05 & 3.21 & 29.77 \\
\hline ECA & 6.12 & 6.37 & 12.49 & 2.06 & 3.66 & 2.65 & 48.98 & 63.06 \\
\hline LAC & 26.07 & 28.55 & 54.62 & 7.82 & 22.38 & 11.85 & 47.73 & 72.33 \\
\hline MNA & 0.77 & 4.29 & 5.07 & 0.61 & 3.76 & 2.09 & 15.29 & 52.82 \\
\hline SAS & 113.77 & 384.99 & 498.76 & 37.37 & 43.74 & 42.10 & 22.81 & 25.70 \\
\hline India & 100.50 & 326.21 & 426.71 & 42.70 & 49.13 & 47.45 & 23.55 & 26.17 \\
\hline SSA & 66.42 & 206.73 & 273.15 & 40.21 & 53.07 & 49.24 & 24.32 & 29.78 \\
\hline Total & 241.53 & 1038.10 & 1279.63 & 13.84 & 36.64 & 27.95 & 18.88 & 38.12 \\
\hline Less China & 230.55 & 706.72 & 937.27 & 16.28 & 35.61 & 27.56 & 24.60 & 41.64 \\
\hline \multicolumn{9}{|l|}{2002} \\
\hline EAP & 15.82 & 217.76 & 233.58 & 2.22 & 19.84 & 13.00 & 6.62 & 38.79 \\
\hline China & 4.00 & 175.01 & 179.01 & 0.80 & 22.44 & 13.98 & 2.24 & 37.68 \\
\hline ECA & 2.48 & 4.94 & 7.42 & 0.83 & 2.87 & 1.57 & 33.40 & 63.45 \\
\hline LAC & 38.33 & 26.60 & 64.93 & 9.49 & 21.15 & 12.26 & 59.03 & 76.24 \\
\hline MNA & 1.21 & 4.88 & 6.09 & 0.75 & 3.82 & 2.11 & 19.87 & 55.75 \\
\hline SAS & 134.76 & 407.03 & 541.79 & 34.61 & 40.31 & 38.72 & 24.87 & 27.83 \\
\hline India & 115.86 & 328.85 & 444.70 & 39.33 & 43.61 & 42.41 & 26.05 & 28.09 \\
\hline SSA & 98.84 & 228.77 & 327.61 & 40.38 & 50.86 & 47.17 & 30.17 & 35.24 \\
\hline Total & 291.44 & 889.99 & 1181.43 & 13.18 & 29.74 & 22.73 & 24.55 & 42.34 \\
\hline Less China & 287.44 & 714.98 & 1002.42 & 16.80 & 32.29 & 25.57 & 28.52 & 43.40 \\
\hline
\end{tabular}

Note: For region identifiers see Table 1. Source: Ravallion, Chen and Sangraula (2007). 
Table 4: Urban and rural poverty measures using a poverty line of $\$ 2$ a day

\begin{tabular}{|c|c|c|c|c|c|c|c|}
\hline & \multicolumn{3}{|c|}{ Number of poor in millions } & \multicolumn{3}{|c|}{ Headcount index (\%) } & \multirow{2}{*}{$\begin{array}{l}\text { Urban share } \\
\text { of the poor } \\
\text { (\%) }\end{array}$} \\
\hline & Urban & Rural & Total & Urban & Rural & Total & \\
\hline \multicolumn{8}{|l|}{1993} \\
\hline EAP & 199.61 & 976.38 & 1175.99 & 38.55 & 85.07 & 70.61 & 16.97 \\
\hline China & 117.33 & 752.19 & 869.52 & 35.57 & 88.64 & 73.79 & 13.49 \\
\hline ECA & 43.60 & 34.49 & 78.09 & 14.68 & 19.83 & 16.58 & 55.83 \\
\hline LAC & 75.92 & 60.35 & 136.28 & 22.77 & 47.30 & 29.56 & 55.71 \\
\hline MNA & 15.96 & 40.82 & 56.78 & 12.49 & 35.75 & 23.46 & 28.11 \\
\hline SAS & 240.82 & 771.19 & 1012.00 & 79.10 & 87.62 & 85.43 & 23.80 \\
\hline India & 197.05 & 608.07 & 805.12 & 83.73 & 91.58 & 89.52 & 24.47 \\
\hline SSA & 110.45 & 331.96 & 442.41 & 66.86 & 85.22 & 79.75 & 24.97 \\
\hline Total & 686.36 & 2215.19 & 2901.55 & 39.32 & 78.19 & 63.37 & 23.65 \\
\hline Less China & 569.04 & 1463.00 & 2032.03 & 40.19 & 73.72 & 59.76 & 28.00 \\
\hline \multicolumn{8}{|l|}{2002} \\
\hline EAP & 126.26 & 708.43 & 834.69 & 17.71 & 63.22 & 45.56 & 15.13 \\
\hline China & 53.45 & 507.48 & 560.93 & 10.68 & 65.07 & 43.81 & 9.53 \\
\hline ECA & 32.07 & 32.22 & 64.29 & 10.71 & 18.69 & 13.63 & 49.88 \\
\hline LAC & 111.08 & 58.36 & 169.44 & 27.51 & 46.39 & 31.99 & 65.56 \\
\hline MNA & 19.90 & 48.12 & 68.02 & 12.36 & 37.64 & 23.54 & 29.25 \\
\hline SAS & 296.55 & 880.80 & 1177.35 & 76.16 & 87.22 & 84.15 & 25.19 \\
\hline India & 236.07 & 672.29 & 908.36 & 80.14 & 89.15 & 86.62 & 25.99 \\
\hline SSA & 167.72 & 370.83 & 538.55 & 68.52 & 82.45 & 77.54 & 31.14 \\
\hline Total & 751.75 & 2098.76 & 2850.51 & 33.99 & 69.80 & 54.64 & 26.37 \\
\hline Less China & 698.29 & 1591.29 & 2289.58 & 40.81 & 71.45 & 58.16 & 30.50 \\
\hline
\end{tabular}

Note: For region identifiers see Table 1. Source: Ravallion, Chen and Sangraula (2007). 